\title{
Comparative Study of Coagulation Profile in Benign and Malignant Neoplasms in Bhopal, India
}

\author{
Rajni Choudhary¹, Seema Jathapi², R. K. Nigam³ ${ }^{3}$ Reeni Malik ${ }^{4}$, Ravi Kumar Meena ${ }^{5}$ \\ 1,2, 3, 4, 5 Department of Pathology, Gandhi Medical College, Bhopal, Madhya Pradesh, India.
}

\section{ABSTRACT}

\section{BACKGROUND}

Thrombosis is a well-recognized and common complication in patients with malignant disease and can contribute significantly to the morbidity and mortality of this disease. We wanted to compare the coagulation parameters in benign and malignant neoplasms.

\section{METHODS}

A comparative study was done and a total of 230 cases ( 75 benign and 155 malignant) and 120 controls were evaluated. After processing the blood samples, various tests like complete blood count, platelet count, prothrombin time (PT), activated partial thromboplastin time (APTT), fibrin degradation product (FDP), and D-Dimer were done.

\section{RESULTS}

Significant differences were noted in the coagulation parameters of both the groups. Malignant cases show abnormal coagulation parameters as compared to control group. Mean platelet count - control - $250+/-61$, cases $-375+/-100$, mean PT control $-14.1+/-6 \mathrm{~s}$, cases $-15.2+/-1.2 \mathrm{~s}$, mean APTT- control $-29.5+/-1.3 \mathrm{~s}$, cases $-34.8+/-2.5 \mathrm{~s}$.

\section{CONCLUSIONS}

Cancer is associated with a high risk of thrombotic complications. Altered coagulation parameters significantly correlate with malignant nature of tumour and also their spread. Preventing this complication is clinically relevant because it significantly contributes to morbidity and mortality in these patients.
Corresponding Author: Dr. Seema Jathapi, Department of Pathology, Gandhi Medical College, Bhopal, Madhya Pradesh, India.

E-mail: seema.jatthapi@gmail.com

DOI: $10.14260 / j e m d s / 2021 / 345$

How to Cite This Article:

Choudhary R, Jathapi S, Nigam RK, et al. Comparative study of coagulation profile in benign and malignant neoplasms in Bhopal, India. J Evolution Med Dent Sci 2021;10(22):1662-1666, DOI: 10.14260/jemds/2021/345

Submission 25-07-2020,

Peer Review 07-04-2021, Acceptance 13-04-2021, Published 31-05-2021.

Copyright (C) 2021 Seema Jathapi et al. This is an open access article distributed under Creative Commons Attribution License [Attribution 4.0 International (CC BY 4.0)]

\section{KEY WORDS}

Coagulation, Neoplasm, FDP, D-Dimer, Thrombosis 


\section{BACKGROUND}

Armand Trousseau first reported on the relationship between thrombosis and cancer in $1865 .{ }^{1}$ Since then, numerous studies have established that thrombosis is a common complication for cancer patients, contributing to the second-leading cause of mortality in cancer patients. ${ }^{2,3}$ Thrombosis is a wellrecognized and common complication in patients with malignant disease and can contribute significantly to the morbidity and mortality of this disease. Thrombotic complications in cancer can vary from arterial or venous thromboembolism to disseminated intravascular coagulation. 3,4

Despite the well-known association between cancer and thromboembolic disease, the mechanisms that promote thromboembolic events in cancer patients are not clear and appear to be multifaceted. The tumours through the production of procoagulant factors and the host through the inflammatory response participate in the process. The relation between cancer and coagulation is categorized by some mechanisms signifying that tumour biology and coagulation are closely linked processes. The pathogenesis of blood coagulation activation in cancer is complex and multifactorial.

However, a unique feature in malignancy is the role played by the expression of tumour cell-associated clot promoting properties. These properties lead to the activation of the clotting cascade, with the generation of thrombin and fibrin, and the stimulation of platelets, leukocytes and endothelial cells which expose their cellular procoagulant features. 4,5 Cancer patients are generally in a hypercoagulable or prothrombotic state, as they usually present with abnormalities in each component of Virchow's triad, thus contributing to thrombosis.

The three components are a stasis of blood flow, endothelial injury, and hypercoagulability, the latter including abnormalities in the coagulation and fibrinolytic pathway and platelet activation. The specific mechanisms leading to abnormalities in Virchow's triad in cancer patients, particularly the effect on the host haemostatic system to promote the prothrombotic state, are not well understood and may be tumour specific as different cancer types have varying risk rates for cancer-associated thrombosis. ${ }^{6}$ It is now well known that the clinical manifestation of thrombosis in this condition can be very different and vary from localized venous thromboembolism to disseminated intravascular coagulation. In addition, a subclinical activation of blood coagulation or "hypercoagulable state" is present in almost all cancer patients, even without symptoms of thrombosis.

The activation of blood coagulation in those with malignant disease appears to be dependent upon the elaboration of tumour-derived tissue factors resulting in an activation of extrinsic pathway of coagulation cascade.6,7 Assessment of the coagulation profile in cancer might help understanding their relationship with coagulation abnormalities and in the prediction as well as management of complications arising from them.

We wanted to compare the coagulation parameters in benign and malignant neoplasms.

\section{METHODS}

This comparative study was conducted in the Dept. Of Pathology, Gandhi Medical college, Bhopal from 1 $1^{\text {st } J a n} 2018$ to $30^{\text {st }}$ June 2019. During the study period, a total of 230 cases (75 benign and 155 malignant) and 120 Control were evaluated. Sample size was taken based on the convince of the study. Patients were selected according to the inclusion and exclusion criteria. After taking informed consent, all the patients were subjected to history and examination after which they were investigated for all the parameters detailed below.

\begin{tabular}{|cc|}
\hline Malignant Cases & Total No. \\
Breast Ca. & 50 \\
Ca.Cervix & 32 \\
Endometrial ca. & 10 \\
Ovarian ca. & 12 \\
Ca. U.Bladder & 8 \\
Prostate ca. & 3 \\
GIT malignancy & 10 \\
Oral cavity ca. & 30 \\
\hline Table 1. Malignant Cases Diagnosed on Histopathology \\
\hline
\end{tabular}

\section{Inclusion Criteria}

Patient with benign and malignant lesions and normal individuals attending Hamidia Hospital who gave consent.

\section{Exclusion Criteria}

Cases of any disease other than malignancy which can alter the coagulation profile and patients who are on anticoagulant medication or taking medication which can alter coagulation profile were excluded.

Blood sample was collected in ethylene diamine tetra acetic acid (EDTA) vial ( $9: 1$ ratio of blood and anticoagulant) for evaluation of haematological analysis. (complete blood count, total leucocyte count and platelet count). Blood sample was collected in citrate vial $(9: 1$ ratio of blood and anticoagulant) for coagulation parameters. The plasma isolated from the sample was used for evaluation of -

- Prothrombin Time,

- Activated partial thromboplastin time,

- Fibrin degradation products,

- D-Dimer.

- (Plasma was transferred to vials, frozen and stored at - 40 degree Celsius until evaluated).

The reference ranges in our laboratory -

- Platelet count: 150,000 - 400,000 / mm3

- $\mathrm{PT}=11-15 \mathrm{~s}$

- $\quad$ APTT $=27-35 \mathrm{~s}$,

- Plasma D-dimer concentration $<0.5 \mu \mathrm{g} / \mathrm{mL}$.

- FDP, being a qualitative test, gives result as either positive or negative

\section{Statistical Analysis}

Data was managed and analysed by using statistical packages for social sciences (SPSS). Different codes were assigned to them, for categorical variables. Arithmetic mean, Standard 
deviation (SD), Student t-test and probability value (P value) was performed.

\section{RESULTS}

During the study period, a total of 230 cases ( 75 benign and 155 malignant) and 120 control were evaluated. Control - It included healthy subjects with age, sex and socioeconomically matched controls from hospital staff and patients relative.

In the control group, the mean \pm SD value of $\mathrm{Hb}$ was $12.8 \pm$ 1.10 with a range of $11.0-15.6 \mathrm{~g} / \mathrm{dl}$ and in benign cases the mean \pm SD value of $\mathrm{Hb}$ was $12.1 \pm .98$ with a range of $9.9-14.8$ $\mathrm{g} / \mathrm{dl}$ subjects with malignancy, the mean \pm SD value of $\mathrm{Hb}$ was $10.3 \pm 2.18$ with a range of $3.9-14.2 \mathrm{~g} / \mathrm{dl}$. On comparison with control, malignancies showed statistically significant decreased $\mathrm{Hb}$ level $(\mathrm{P}<0.001)$. The mean $\pm \mathrm{SD}$ values of TLC in controls was $7.61 \pm 1.46$ with a range of $4.5-10.2 \times 10^{9} / \mathrm{L}$ and in benign and malignant cases was $7.42 \pm 1.60$ with a range of $4.2-13.3 \times 10^{9} / \mathrm{L}$ and $7.38 \pm 1.80 \&$ range $3.5-14.0 \times 10^{9} / \mathrm{L}$ respectively, but no significant difference (P value $>0.05$ )

\begin{tabular}{|c|c|c|c|}
\hline \multirow{2}{*}{$\begin{array}{c}\text { Platelet Count } \\
\text { (in Lakhs/Cumm) }\end{array}$} & \multirow[t]{2}{*}{ Control } & \multicolumn{2}{|c|}{ Cases } \\
\hline & & Benign & Malignant \\
\hline$<1.5$ & $00(00 \%)$ & $06(8.0 \%)$ & 08 (5.1\%) \\
\hline $1.5-4.0$ & $120(100 \%)$ & $64(85.3 \%)$ & $63(40.7 \%)$ \\
\hline$>\quad 4.0$ & $00(00 \%)$ & $05(6.7 \%)$ & $84(54.2 \%)^{*}$ \\
\hline Total & $120(100 \%)$ & $75(100 \%)$ & $155(100 \%)$ \\
\hline \multicolumn{4}{|c|}{ Table 1. Distribution of Patients According to Platelet Count } \\
\hline
\end{tabular}

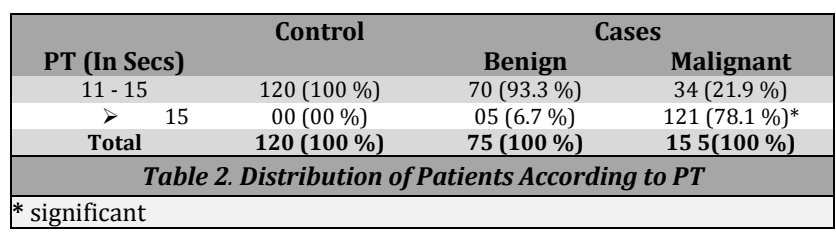

\begin{tabular}{|cccc|}
\hline & Control & \multicolumn{2}{c|}{ Cases } \\
APTT (in Secs) & & Benign & Malignant \\
$27-35$ & $120(100 \%)$ & $73(97.3 \%)$ & $43(27.7 \%)$ \\
$>35$ & $00(00 \%)$ & $02(2.7 \%)$ & $112(72.3 \%)^{*}$ \\
Total & $\mathbf{1 2 0}(\mathbf{1 0 0} \%)$ & $\mathbf{7 5}(\mathbf{1 0 0} \%)$ & $\mathbf{1 5 5}(\mathbf{1 0 0} \%)$ \\
\hline Table & 3. Distribution of Patients According to APTT \\
\hline * significant & & \\
\hline
\end{tabular}

$85.3 \%$ of the benign cases and $40.7 \%$ of the malignant cases have platelet count in the normal range. Only $6.7 \%$ of benign cases whereas $54.2 \%$ of the malignant cases showed thrombocytosis (platelet count more than 4.0 lakhs/Cumm (P value $<0.001$ ) $100 \%$ of the control \& $93.3 \%$ of benign cases have PT in the normal range while only $21.9 \%$ malignant cases have PT in the normal range. $78.1 \%$ of the malignant cases have PT above 15 sec. Thus malignancies exhibited significantly elevated PT when compared with control group and benign lesions. (P value $<0.001$ ).

$100 \%$ \& $97.3 \%$ of control \& benign cases have APTT in the normal range respectively, while $27.7 \%$ of malignant cases have APTT in the normal range and $72.3 \%$ have APTT above 35 secs. Thus malignancies exhibited statistically significant elevated APTT when compared with control group and benign lesions (P Value $<0.001$ ). All of the control \& benign cases have negative FDP, while $48.4 \%$ of the malignant cases have positive FDP. The $\chi 2$-test was applied on the FDP values, which showed statistically significant difference. (P Value < 0.001). D-Dimer in all the control \& benign group were in the range of $<200 \mathrm{ng} / \mathrm{ml}$. In patients with malignancy, 12 out of 155 (7.74 \%) have D - Dimer in the range of $200-500 \mathrm{ng} / \mathrm{ml}$, 63 out of 155 (40.6\%) have D-Dimer in the range of 500 $1000 \mathrm{ng} / \mathrm{ml}$, while 80 out of 155 (51.6\%) were in the range of $<200 \mathrm{ng} / \mathrm{ml}$.

\begin{tabular}{|ccccccccccc|}
\hline \multicolumn{4}{c}{ Control } & \multicolumn{3}{c}{ Benign } & \multicolumn{3}{c|}{ Malignant } \\
Variable Mean & SD+ / & SEM & Mean & SD+ / & SEM & Mean & SD+ / & SEM \\
Hb & 12.8 & 1.10 & .101 & 12.1 & 1.80 & .114 & 10.3 & 2.186 & .175 \\
PLT & 2.50 & .6151 & .0561 & 2.6 & .658 & .075 & 3.95 & 1.00 & .102 \\
PT & 13.5 & .5052 & .0461 & 14.0 & .6526 & .075 & 15.8 & 1.18 & .095 \\
APTT & 29.5 & 1.31 & .1523 & 30.0 & 2.55 & .105 & 35.6 & 2.55 & .205 \\
\hline \multicolumn{4}{|c}{ Table 4. Statistical Comparison } \\
\hline
\end{tabular}

Comparison between the control group \& benign lesions were insignificant whereas malignant cases showed statistically significant difference. ( $P$ value $<0.001$ ) when compared with control group and benign lesions. $70 \%$ endometrial carcinoma followed by $58.3 \%$ of ovarian carcinoma, $54 \%$ of breast cancers \& $50 \%$ of GIT malignancy had a higher FDP positivity. 54 out of 75 FDP positive cases have lymph node involvement and also the mean D-dimer values was higher \& statistically significant. (P value $<0.001)$.

\begin{tabular}{|ccc|}
\hline Lymph Node & No. of Cases & Mean D-Dimer \\
Involved & 54 & $0.780 \mathrm{ug} / \mathrm{ml}^{*}+/-0.22$ \\
Not involved & 21 & $0.356 \mathrm{ug} / \mathrm{ml}+/-0.20$ \\
Table 5. Lymph Node Status in FDP Positive Cases \\
\hline
\end{tabular}

\section{DISCUSSION}

Cancer is a prothrombotic state. Experimental and clinical studies have shown an association between cancer and haemostasis, which is altered and provides a growth benefit to tumours, although clinical symptoms occur less often. The pathogenesis of blood coagulation activation in cancer is complex and multifactorial. However, a unique feature in malignancy is the role played by the expression of tumour cellassociated clot promoting properties. These properties lead to the activation of the clotting cascade, with the generation of thrombin and fibrin, and the stimulation of platelets, leukocytes and endothelial cells which expose their cellular procoagulant features. ${ }^{4,8}$ The tumours, through the production of procoagulant factors, and the host, through its inflammatory response, participate in the process. Abnormal coagulation activation encourages endothelial adhesion, metastatic spread, tumor cell growth, and survival.

In this study we studied the hemostatic and coagulation profile in 230 cases ( 155 haved malignancies, 75 haved benign lesions, and 120 were apparently normal controls). Complete blood count, PT, APTT, D - Dimer, and FDP were done.

Mohammed et al. ${ }^{9}$ showed that mean platelet count in cancer was $317.8+/-23.46 \times 10^{3} / \mathrm{cm}$ and in control group was $260.7+/-7.96 \times 10^{3} / \mathrm{cm}$. Amin et al. ${ }^{10}$ showed that the mean platelet count $286+/-144 \times 10^{3} / \mathrm{cm}$ in malignancies in comparison with the control group $\left(212+/-46 \times 10^{3} / \mathrm{cm}\right)$. However, Omer and Abdalla ${ }^{11}$ showed the mean platelet count in cancer was $249.6+/-142.3 \times 10^{3} / \mathrm{cm}$, while for the control group, it was $279.7+/-77.9 \times 10^{3} / \mathrm{cm}$. Patel et al. ${ }^{12}$ showed the mean platelet count in malignancies was $334.14+/-104.56$ and in controls $273.73+/-126.52 \times 10^{3} / \mathrm{cm}$. 


\begin{tabular}{|c|c|c|c|c|c|c|}
\hline \multirow[t]{2}{*}{ Study } & \multicolumn{2}{|c|}{ Mean PLT / SD } & \multicolumn{2}{|c|}{ Mean PT / SD } & \multicolumn{2}{|c|}{ Mean APTT / SD } \\
\hline & Control & Cases & Control & Cases & Control & Cases \\
\hline Mohammed et al. & $260.7+/-7.96$ & $317.8+/-23.46$ & $12.9+/-0.27 \mathrm{~s}$ & $15+/-0.32 s$ & $35.1+/-0.56 \mathrm{~s}$ & $35.1+/-0.56 \mathrm{~s}$ \\
\hline Amin et al. & $212+/-46$ & $286+/-144$ & $13+/-1 s$ & $15+/-3 s$ & & \\
\hline Omer \& Abdalla et al. & $279.7+/-77.9$ & $249.6+/-142.3$ & $12.2+/-0.8 s$ & $13.7+/-1.3 s$ & $29.6+/-2.2 \mathrm{~s}$ & $35.7+/-6.6 s$ \\
\hline Patel et al. & $273.73+/-126.52$ & $334.14+/ 104.56$ & $12.9+/-0.27 \mathrm{~s}$ & $15.0+/-3.2 \mathrm{~s}$ & $32.95+/-2.25 \mathrm{~s}$ & $46.43+/-18.8 s$ \\
\hline Present study & $250+/-61$ & $375+/-100$ & $14.1+/-6 s$ & $15.2+/-1.2 \mathrm{~s}$ & $29.5+/-1.3 \mathrm{~s}$ & $34.8+/-2.5 s$ \\
\hline & & Table 6. $C$ & ison of Coagu & Parameters & & \\
\hline
\end{tabular}

In our study, the mean platelet count in malignancies was $375+/-100 \times 10^{3} / \mathrm{cm}$, which was higher when compared with apparently normal controls $250+/-61 \times 10^{3} / \mathrm{cm}$ and benign disease $260+/-65 \times 10^{3} \mathrm{~cm}$. The comparison between normal \& benign group was not significant, whereas comparison between normal \& malignant cases was statistically significant (P value < 0.001).

Mohammed et al. ${ }^{9}$ showed that mean PT in cancer was 15 $+/-0.32 \mathrm{~s}$ and in control group was $12.9+/-0.27 \mathrm{~s}$. Amin et al. ${ }^{10}$ showed that the mean PT was $15+/-3 \mathrm{~s}$ in malignancies group when compared with the control group with a mean PT of $13+/-1 \mathrm{~s}$. Omer and Abdalla ${ }^{11}$ showed that the mean PT in cancer was $13.7+/-1.3 \mathrm{~s}$, while in control group, it was 12.2 $+/-0.8 \mathrm{~s}$. Patel et al. ${ }^{12}$ showed the mean PT in malignancies was $15.0+/-3.2 \mathrm{~s}$ and in controls $12.9+/-0.27 \mathrm{~s}$

In our study, the mean PT in malignancies was $15.8+$ /$1.18 \mathrm{~s}$, higher in comparison with the patients with apparently normal controls \& benign group $(14.1+/-6 \mathrm{~s}$ and $13.5+/-5 \mathrm{~s}$ respectively). In our study, malignancies showed statistically significant difference in the mean PT values ( $\mathrm{P}$ value $<0.001$ ).

Mohammed et al. ${ }^{9}$ showed that mean APTT in cancer was $37.9+/-0.31 \mathrm{~s}$ and in control group was $35.1+/-0.56 \mathrm{~s}$. Omer and Abdalla ${ }^{11}$ showed that the mean APTT in cancer was 35.7 $+/-6.6 \mathrm{~s}$ and in the control group was $29.6+/-2.2 \mathrm{~s}$. Patel et al. ${ }^{12}$ showed the mean APTT in malignancies was $15.0+/-3.2 \mathrm{~s}$ and in controls $12.9+/-0.27 \mathrm{~s}$

In our study, the mean APTT in malignancies was $34.8+/-$ $2.5 \mathrm{~s}$, higher in comparison with apparently normal controls $29.5+/-1.3 \mathrm{~s}$ and benign lesions $30.0+/-2.55$ s.In our study, there was statistically significant difference in the mean APTT values of the control group and patients with malignancies, (Pvalue $<0.001$ ).

D-dimer, the main breakdown fragment of fibrin, is a biochemical marker of thrombogenesis and fibrin turnover. High D-dimer is an indirect marker of hyper coagulation activation and thrombolysis. Procoagulant factors in cancer cause constitutive activation of the coagulation cascade leading to thrombin and fibrin generation. Fibrin formation and remodelling process provides extra cellular matrix essential for the initial step of cancer cell to migrate, invade, and metastasize.

Amin et al. showed the mean D-dimer was $3.708+/-3.26$ $\mu \mathrm{g} / \mathrm{mL}$ in malignancies in comparison with the control group $(0.325+/-0.365 \mu \mathrm{g} / \mathrm{mL})$. Omer and Abdalla showed the mean D-dimer in cancer was $2.19632+/-2.11095 \mu \mathrm{g} / \mathrm{mL}$, while for the control group mean D-dimer was $0.21365+/-0.10357$ $\mu \mathrm{g} / \mathrm{mL}$. Mohammed et al. showed D-dimer in cancer was $2-4$ $\mu \mathrm{g} / \mathrm{mL}$ and in control group was $<0.5 \mu \mathrm{g} / \mathrm{mL}$. Suega and Bakta showed the mean D-dimer was $1.260 \mu \mathrm{g} / \mathrm{mL}$ in malignancies.

In our study, statistically significant difference in the mean D-dimer of patients with malignancies $(0.446+/-0.26 \mu \mathrm{g} / \mathrm{mL})$ and the control group $(0.2+/-0.00 \mu \mathrm{g} / \mathrm{mL}$ ) was noted. (Pvalue $<0.001$ ).

Plasma D-dimer correlates with tumour burden, no. of metastatic sites, progression kinetics, cytokines related to angiogenesis ${ }^{13}$ invasion depth, lymph node metastasis, peritoneal dissemination, distant metastasis, tumor size, and TNM stage. ${ }^{13}$ Blackwell et al. ${ }^{14,7}$ showed $75.75 \%(\mathrm{~N}=25$ / 33) of patients with involved lymph nodes had elevated D-dimer. Patel et al. showed (83.33 \%, N = $10 / 12$ ) of patients with involved lymph nodes had elevated $\mathrm{D}$-dimer.

In our study, there were 75 patients with malignancies in which the status of lymph node involvement was available. Of the 75 cases, 54 showed tumour involvement in lymph nodes, while 21 were negative. The mean D-dimer was $0.780+/-0.24$ $\mu \mathrm{g} / \mathrm{mL}$ and $0.35+/-0.21 \mu \mathrm{g} / \mathrm{mL}$ respectively, which showed a significant difference (P value $<0.001)$. Given its sensitivity for predicting positive lymph node involvement, a role of $\mathrm{D}$-dimer, along with other predictive factors to decide whether lymph node dissection is needed may be used.13

The $\chi 2$-test was applied on the FDP values of control and malignant cases, which was statistically significant. (P value < 0.001 )

\section{CONCLUSIONS}

Tumor cells interact with all parts of the hemostatic system. They can directly activate the coagulation cascade by producing their own procoagulant factors, or they can stimulate the prothrombotic properties of other blood cell components. Additional mechanisms of clotting activation are initiated by cytotoxic chemotherapy or other cancer therapies. ${ }^{7}$ Assessment of the coagulation profile in cancer might help in understanding their relationship with coagulation abnormalities and in the prediction as well as management of complications arising from them.

Present study implies a relation between activation of hemostasis shown by elevated D-dimer, altered coagulation profile and malignancy. D-dimer and deranged coagulation profile might be used as universal surrogate indicator of the relation between cancer and the activation of hemostasis and fibrinolysis, with elevated D-dimer levels indicate the pathogenesis of a more aggressive malignant process associated with poor clinical results.

Data sharing statement provided by the authors is available with the full text of this article at jemds.com.

Financial or other competing interests: None.

Disclosure forms provided by the authors are available with the full text of this article at jemds.com.

\section{REFERENCES}

[1] Trousseau A. Phlegmasia alba dolens. Hotel Dieu Paris: Clin Med 1865;3:654-712.

[2] Prandoni P, Falanga A, Piccioli A. Cancer and venous thromboembolism. Lancet Oncol 2005;6(6):401-10. 
[3] Noble S, Pasi J. Epidemiology and pathophysiology of cancer-associated thrombosis. $\mathrm{Br}$ J Cancer 2010;102(Suppl 1):S2-9.

[4] Levi M. Cancer-related coagulopathies. Thromb Res 2014;133(Suppl 2):S70-5.

[5] Donati MB. Cancer and thrombosis. Haemostasis 1994;24(2):128-31.

[6] Eichinger S. Cancer associated thrombosis: risk factors and outcomes. Thromb Res 2016;140(Suppl 1):S12-7.

[7] Falanga A, Marchetti M, Russo L. The mechanisms of cancer-associated thrombosis. Thromb Res 2015;135(Suppl 1):S8-11.

[8] Hoffman R, Haim N, Brenner B. Cancer and thrombosis revisited. Blood Rev 2001;15(2):61-7.

[9] Liao JK. Linking endothelial dysfunction with endothelial cell activation. J Clin Invest 2013;123(2):540-1.
[10] Savage B, Cattaneo M, Ruggeri ZM. Mechanisms of platelet aggregation. Curr Opin Hematol 2001;8(5):270-5.

[11] Amin AM, Getta HA, Abdulsalam AH. Diagnosis of chronic disseminated intravascular coagulation in 72 cancer patients according to the International Society on thrombosis and hemostasis score system. Iraqi J Comm Med 2012;2:136-40.

[12] Mohammed MR, Mansoor SS, Taher MG. Hemostatic derangements in patients with solid malignant tumors. J Pioneering Med Sci 2013;3(1):1-9.

[13] Omer AOA, Abdalla MHA. Evaluation of haemostatic abnormalities among sudanese patients with haematologic and solid malignancy. Am J Med Med Sci 2014;4(5):150-3.

[14] Patel SM, Gupta S, Patel MM, et al. A study of coagulation profile in neoplastic conditions. Int J Med Sci Public Health 2016;5(3):402-7. 